\title{
Proceedings From
}

SEMANTICS

AND

LiNGUISTIC

THEORY

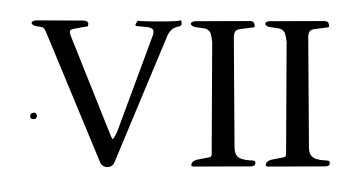

EDITED BY

AARON LAWSON

Cornell University

ITHACA 1997 


\section{•}




\section{ACKNowledgments}

This proceedings contains papers presented at the seventh conference on Semantics and Linguistic Theory, held on March 21-23, 1995, at Stanford University.

The conference was made possible by funds from the School of Humanities and Sciences, the Department of linguistics, the Department of Philosophy, and the Center for the Study of Language and Information, all of Stanford University. and the Graduate School Association at Rutgers University. We would also like the thank The Linguistic Research Center of the University of California at Santa Cruz and the Palo Alto Research Center of the Xerox Corporation for their generous support. Of course, this conference could not have happened without the efforts of the Administrative Staff Members and volunteers. Many thanks to them for their hard work, and to the reviewers who had the difficult job of choosing a few abstracts out of the many submitted.

Finally, our thanks to the Field of Linguistics at Cornell University, CLC Publications, Justin Spence and Teresa Galloway for making this publication possible.

Aaron Lawson

Editor

September 1997 
